\title{
IN SITU METAL MIRROR CRYOFIXATION USING A PORTABLE, HAND-HELD INSTRUMENT
}

\section{Lightfoot, Fred G., George Washington University Medical Center, Department of Anatomy, Washington, DC 20037}

With an increasing interest in both immunological procedures and elemental (ion) detection, it is imperative that tissues be preserved in as life-like a state as possible. Up until now the only type instrument available for in situ cryo fixation was various configurations of cryopliers which lacked the ability to control freezing variables. With the introduction of the PS1000 (Delaware Diamond Knives, Inc.), a pneumatically operated hand held slammer, it is now possible to reproducibly fix in situ as well as in vitro and achieve results seen previously only with table top instruments. This instrument is designed to provide a consistent delivery rate through the use of a pneumatically operated piston.

The availability of such an instrument, clearly improves the accuracy of many investigations. Pleural fluid of the lung parenchyma (Figure 1) has been preserved in its natural state (i.e., filled with air). Figure 2 shows a proximal tubule of rat kidney which has been cryogenically preserved in situ. Applications in biological research, materials science and clinical pathology are currently being investigated at several major institutions.

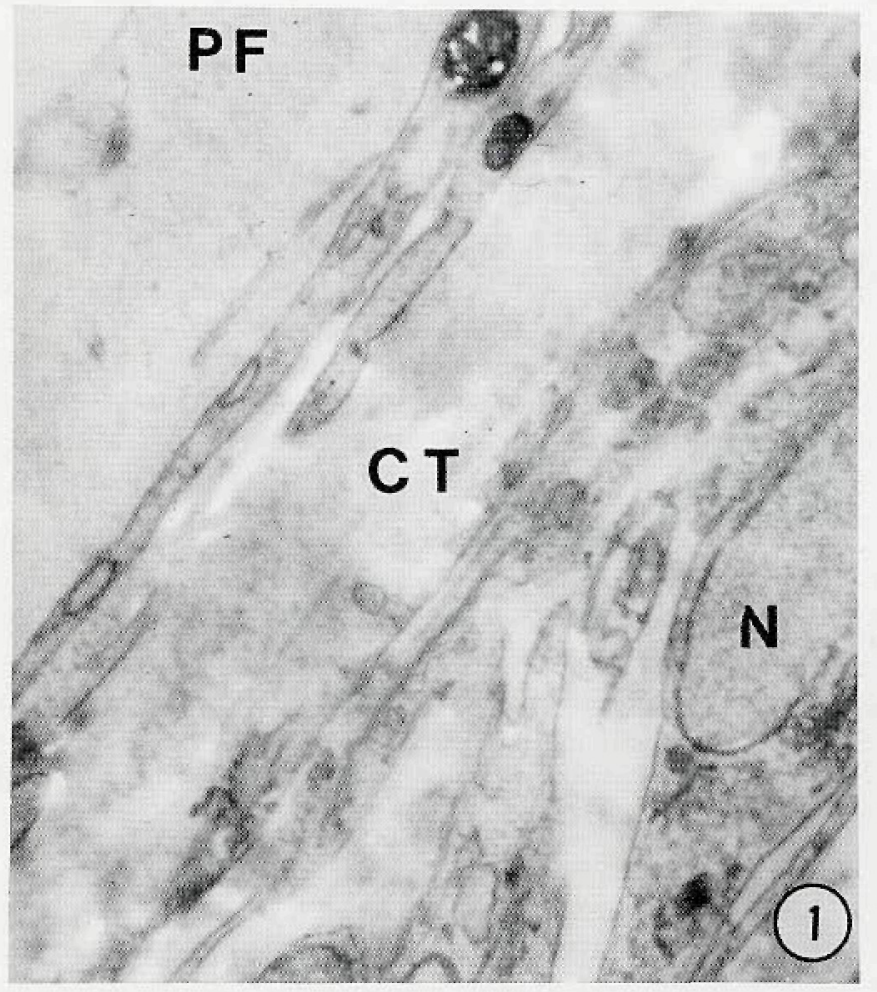

Figure 1 - Cryo-fixed (in situ) lung tissue, freeze-dried and embeded in Spurt resin. $X 30,000$

$\mathrm{PF}=$ Fleural Fluid, $\mathrm{CT}=$ Connective Tissue $\mathrm{N}=$ Nucleus .

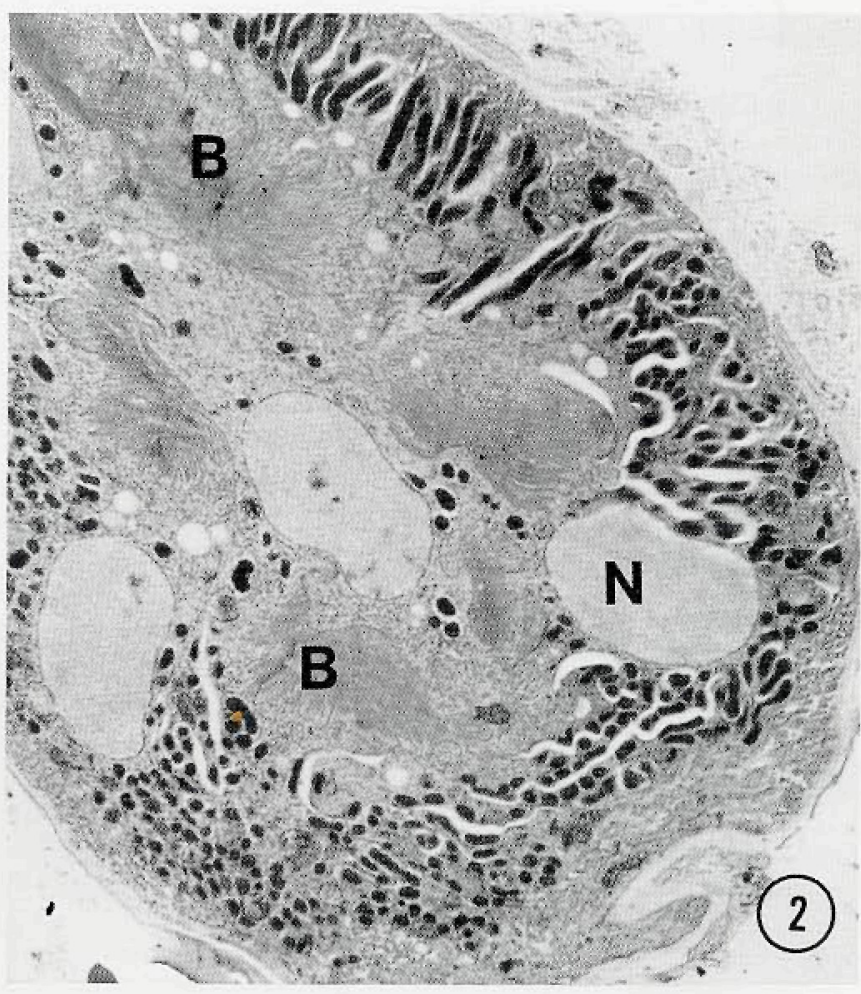

Figure 2 - Cryo-fixed (in situ) kidney proximal tubule, freeze-dried and embedded in Spurr resin. $X=3,400$ $\mathrm{N}=$ Nucleus, $\mathrm{B}=$ Brush Border

\section{EDUCATION OPPORTUNITIES:}

\footnotetext{
$\checkmark$ Madison Area Technical College is initiating (Fall '92) a two year Associate Degree Program in EM. The program stresses hands-on, laboratory experiences using state-ofthe-art equipment. Courses include SEM, TEM, STEM, image processing, $\mathrm{x}$-ray microanalysis, biological sample preparation and non-biological sample preparation. INQUIRIES: Mr. Glen Boda, MATC, 3550 Anderson St., Madison, WI 53704, Tel.: (608)246-6254.
}

$\checkmark \quad$ San Joaquin Delta College offers a two-year associates degree as well as a certificate in electron microscopy, either in the biological field or materials science. Besides core courses, courses include TEM, SEM, EDS, scientific photography, maintenance, biological specialities in ultrastructure, ultramicrotomy, advanced techniques, and materials specialties in preparation of thin foils and electron diffraction. For information, contact: Dr. Judy Murphy, San Joaquin Delta College, EM Dept, 5151 Pacific Ave, Stockton, CA 95207. Tel.: (209)474-5284, Fax: (209)474-5649. 